\section{Books beantiful books}

If you would like to be a Vital book reviewer or submit a publication for review, contact the Editor, Kate Maynard, by emailing k.maynard@nature.com.

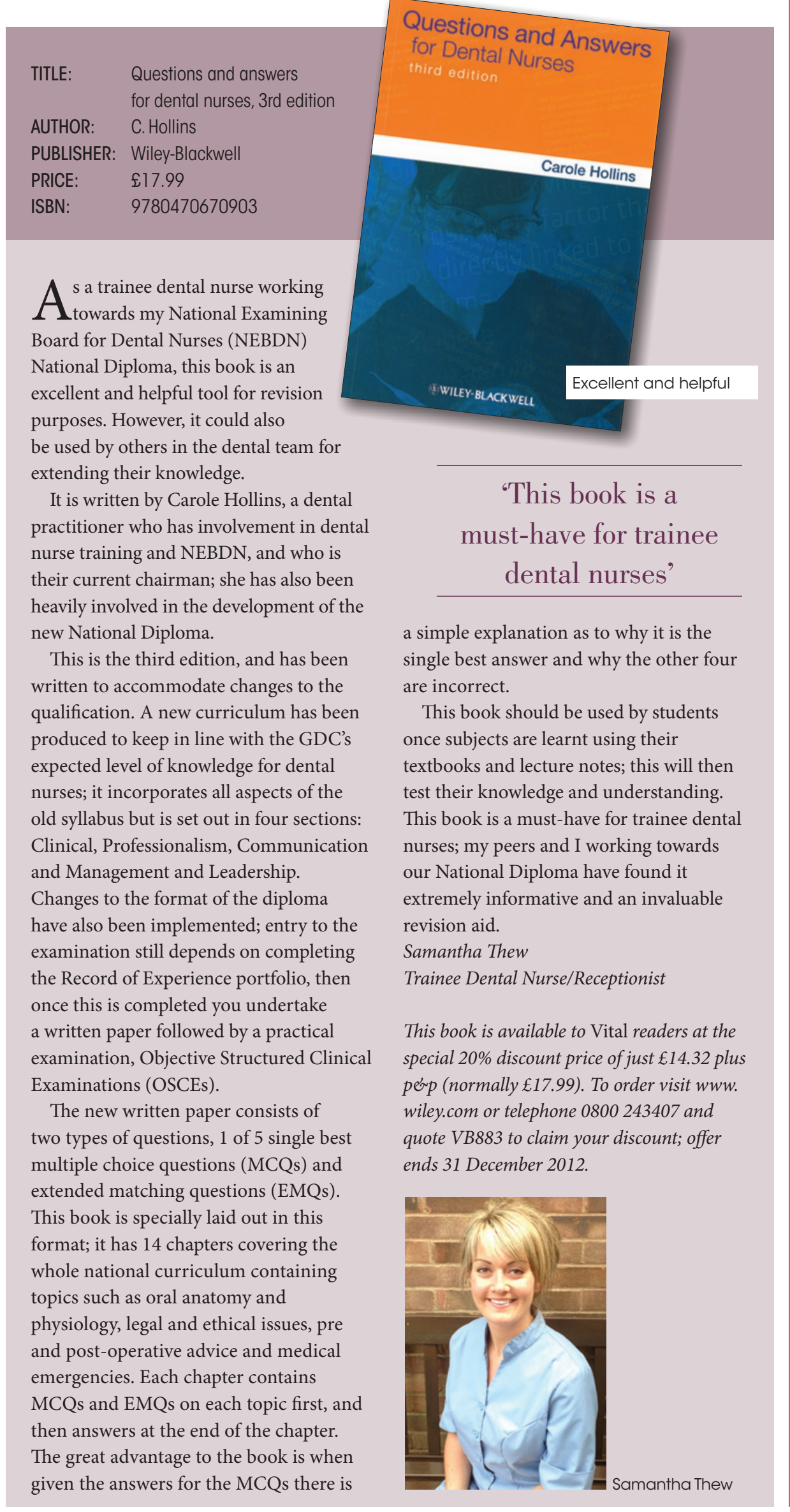

$\begin{array}{ll}\text { TITLE: } & \begin{array}{l}\text { Mosby's comprehensive review } \\ \text { of dental hygiene, 7th edition }\end{array} \\ \text { AUTHOR: } & \text { M. L. Darby } \\ \text { PUBLISHER: } & \text { Elsevier } \\ \text { PRICE: } & £ 41.99 \\ \text { ISBN: } & 9780323079631\end{array}$

$\mathrm{W}$ hen this book arrived my first observation was that it is written to help students pass the National Board Dental Hygiene Examination (NBDHE), the

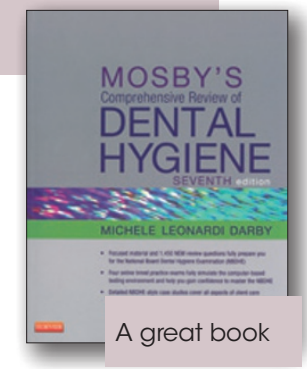

American dental hygiene examination. Due to this fact I was very interested to see if it would be useful for the UK hygienist.

The book follows a logical sequence, comprehensive as the title states, and is written in an easy to follow format. It begins with histology, anatomy and physiology, moving on to dental anatomy, then pathology, pharmacology and last but not least periodontics, dental hygiene, oral health promotion and instrumentation. Leaving it in the staffroom at work I quite often found a member of staff reading a section that interested them (or just looking at the pictures); it is a book you can dip in and out of. It is well illustrated in colour with many pictures and diagrams that are clearly labelled. At the end of each chapter there is test section and the answers can be found on the Evolve website. We spent many a lunchtime testing each other; it was a great refresher of knowledge.

There is a scratch off panel on the inside cover of the book allowing you to register on the Evolve website. It is easy to register your details but it took me some time to understand how to navigate the site to find the area I needed for the study aids. It was worth my patience as I found this area fantastic. There are diagrams to label, flashcards, mock tests, case studies and study aids. You can take as long as you like with these 'tests' and leave them part completed allowing you to return at your convenience to complete them. There is a timer function so you can take a simulated exam, of which there are four on the site.

In conclusion I thought it was a great book which I enjoyed reading in any free time I had. Sometimes I would try to answer the questions at the end of a chapter first and then research any areas I felt my knowledge required refreshing.

The book is 'hefty' so not one to carry around with you, but great to refresh or help students or qualified hygienists increase/ improve their knowledge.

Ru Boyle

Dental Hygienist 